\title{
ANTICUERPOS CONTRA EL VIRUS DE ESTOMATITIS VESICULAR EN HUANGANAS (Tayassu pecari) EN MADRE DE DIOS, PERÚ
}

\author{
Antibodies Against Vesicular Estomatitis Virus in White-Lipped Peccaries \\ (Tayassu pecari) in Madre de Dios, Peru
}

\author{
Susan Carruitero H. ${ }^{1}$, Hermelinda Rivera G. ${ }^{1,3}$, Mercy Ramírez V. ${ }^{1}$, Juan More B. ${ }^{1}$, \\ Alfonso Zúñiga H. ${ }^{2}$, Mónica Romero S. ${ }^{2}$
}

\section{Resumen}

El objetivo del presente estudio fue determinar la presencia de anticuerpos neutralizantes contra los serotipos New Jersey (NJ) e Indiana subtipo 1 (IND-1) del virus Estomatitis Vesicular (VEV) en huanganas (Tayassu pecari) de vida libre de las localidades de Boca de Manu ( $n=30)$, Concesión para la Conservación Los Amigos ( $n=10)$ y La Reserva Nacional Tambopata/Parque Nacional Bahuaja Sonene $(n=48)$ en el departamento de Madre de Dios. La presencia de anticuerpos contra el VEV fue determinado mediante la prueba de neutralización viral en las 88 muestras de suero de huanganas machos y hembras adultos de apariencia normal. El $53.4 \%$ (47/88) y 18.2\% (16/88) de las muestras fue positiva a anticuerpos contra los serotipos IND-1 y NJ, respectivamente, en tanto que el 29.5 y el $2.3 \%$ de las muestras tuvieron anticuerpos neutralizantes igual o mayor a 1:32 contra los serotipos IND-1 y NJ, respectivamente. No hubo asociación significativa entre las variables presencia de anticuerpos contra el VEV y lugar de procedencia de las muestras.

Palabras clave: huangana, Tayassu pecari, virus estomatitis vesicular, anticuerpos, New Jersey, Indiana, neutralización viral, selva baja

\section{Abstract}

The aim of the study was to determine the presence of antibodies against New Jersey (NJ) and Indiana subtype 1 (IND-1) Vesicular Stomatitis Virus (VSV) in free-living white-lipped peccaries (Tayassu pecari) in three localities of Madre de Dios, Peru. The presence of antibodies against VSV by virus neutralization test was determined in 88 serum samples of adult male and females in apparent good health condition. Results showed that $53.4 \%(47 / 88)$ and $18.2 \%(16 / 88)$ of samples were positive to antibodies against serotypes IND-1 and NJ respectively, whereas 55.3 and $12.6 \%$ of the serum samples had neutralizing antibodies titers equal or greater than 1:32 against serotype

\footnotetext{
${ }^{1}$ Laboratorio de Microbiología y Parasitología Veterinaria, Facultad de Medicina Veterinaria, Universidad Nacional Mayor de San Marcos, Lima

${ }^{2}$ Proyecto ÁREAS-Amazonía de la World Wildlife Fund (WWF-Perú)

${ }^{3}$ E-mail: hriverag2005@yahoo.es
} 
IND-1 and NJ respectively. There was a no significant association between seropositivity of VSV and source of samples.

Key words: white-lipped peccary, Tayassu pecari, vesicular stomatitis virus, antibodies, serotype New Jersey, serotype Indiana-1, viral neutralization, jungle

\section{INTRODUCCIÓN}

El virus de la estomatitis vesicular (VEV) pertenece al género Vesiculovirus, familia Rhabdoviridae, y tiene dos serotipos: Indiana-1 (IND-1) y New Jersey (NJ). Infecciones por ambos serotipos se presentan en forma esporádica en EEUU y con mayor frecuencia en el sureste mexicano, Colombia, Venezuela, Ecuador y Perú (Rodríguez, 2002). Asimismo, se reportan casos esporádicos en Argentina y Brasil, donde los agentes etiológicos han sido serológicamente relacionados al serotipo Indiana y han sido clasificados como serotipo Cocal (Indiana 2) y Alagoas (Indiana 3) (Reis et al., 2009).

El virus infecta de forma natural a mamíferos domésticos y silvestres. La mayor ocurrencia de la EV se da en zonas tropicales de América Central y del Sur, tanto al final de la época lluviosa como al inicio de la época seca. Puede tener múltiples reservorios y transmisores, aunque su mecanismo de propagación no es bien conocido (Vanleeuwen et al., 1995).

El Perú cuenta con una gran diversidad de fauna silvestre, especialmente en la zona del trópico. Una de las especies de importancia es la huangana (Tayassu pecari), conocida también como pecarí labiado. Es un mamífero de la familia Tayassuidae (Bodmer et al., 1997) y con un parecido físico al cerdo doméstico. La huangana, además de ser utilizada por su piel y como fuente de proteína, tiene un rol importante en la dinámica del ecosistema, al ser un eficiente dispersor de semillas, manteniendo la diversidad del bosque, y servir de alimento a los grandes carnívoros (Painter, 1996; Bodmer et al., 2004).
La presencia de la huangana ha disminuido en algunos lugares de la Amazonía peruana sin que se haya determinado la causa, pero pareciera que algún agente infeccioso podría estar comprometido (Fragoso, 1997). Estudios serológicos indican que estos animales pueden infectarse con los virus de exantema vesicular y estomatitis vesicular, entre otros, y por bacterias como Brucella spp y Leptospira spp. Además, podrían ser un potencial portador de fiebre aftosa (Karesh et al., 1998; Cleaveland et al., 2002; Beldoménico, 2008; Real et al., 2010; Romero, 2010).

Existen escasos estudios sobre diversos agentes infecciosos que podrían afectar la salud de las huanganas en el Perú. En el estudio de Romero (2010) se investigó serológicamente a agentes infecciosos como Brucella spp, enfermedad de Aujeszky, Peste Porcina Clásica y Toxoplasma gondii, pero no se incluyó al VEV. Por lo tanto, el objetivo del presente estudio fue evaluar la presencia de anticuerpos contra el virus de la estomatitis vesicular en huanganas de vida libre de tres localidades del departamento de Madre de Dios.

\section{Materiales y Métodos}

\section{Animales y Muestras}

Las muestras de suero fueron obtenidas en el periodo 2008-2009 de huanganas de tres áreas protegidas del departamento de Madre de Dios: Boca de Manu, Concesión para la Conservación Los Amigos y Reserva Nacional Tambopata/Parque Nacional Bahuaja Sonene, a una altitud de 200-300 
msnm y con un clima tropical húmedo. Las muestras fueron colectadas durante las labores de campo del Proyecto ÁREASAmazonía de la World Wildlife Fund (WWFPerú), cuyos investigadores contaron con los permisos necesarios de la Dirección de Gestión Forestal y de Fauna Silvestre (DGFFS) del Ministerio de Agricultura y del CITES, ya que la huangana está incluida en el Apéndice II del CITES.

La captura de los animales fue con redes de caída (capturas dirigidas) y trampas de lazo (capturas incidentales) e inmovilizados mediante el uso de Midazolam en dosis $0.2-0.3 \mathrm{mg} / \mathrm{kg}$ de peso $\mathrm{y}$ Medetomidina en dosis $0.04-0.06 \mathrm{mg} / \mathrm{kg}$ de peso, que permitió mantener al animal sedado por aproximadamente 60 minutos, tiempo necesario para los trabajos del proyecto ÁREAS-Amazonía de la World Wildlife Fund (WWF-Perú) y para la colección de sangre. Luego se les aplicó los respectivos fármacos antagonistas Atipamezol en dosis $0.2-0.3 \mathrm{mg} / \mathrm{kg}$ de peso y Flumazenil en dosis $0.01 \mathrm{mg} / \mathrm{kg}$ de peso (World Wildlife Fund, datos por publicarse). Se evitó muestrear a hembras en avanzado estado de gestación y a crías.

La sangre fue colectada de la vena cefálica o de la vena safena utilizando el sistema Vacunatiner® y el suero fue obtenido por centrifugación a $2000 \mathrm{rpm}$ por 5 minutos en el campamento del proyecto y envasados en viales para ser conservados a $-20{ }^{\circ} \mathrm{C}$ antes de ser enviados al laboratorio. El total de muestras colectadas fue 88 de los cuales 30 fueron de Boca de Manu, 10 de Concesión para la Conservación Los Amigos y 48 de la Reserva Nacional Tambopata/Parque Nacional Bahuaja Sonene.

\section{Detección de Anticuerpos contra VEV}

La detección de los anticuerpos contra los serotipos Indiana-1 y New Jersey fueron realizados mediante la prueba de neutralización viral según el protocolo descrito en el Manual de la Organización Mundial de Sani- dad Animal (OIE, 2010). Se utilizaron cepas del virus de estomatitis vesicular serotipo Indiana-1 (IND-1) y New Jersey, con títulos de $10^{-4} \mathrm{DI}_{50} \mathrm{CC} / 50 \mu \mathrm{l}$ y de $10^{-5} \mathrm{DI}_{50} \mathrm{CC} / 50 \mu \mathrm{l}$, respectivamente, y como sistema indicador de la prueba se utilizó la línea celular vero.

El título de suero fue expresado como la dilución más alta capaz de neutralizar $100 \mathrm{DI}_{50} \mathrm{CC} / 50 \mu \mathrm{l}$ del virus, evidenciado por la ausencia de efecto citopático en las células indicadoras. Títulos iguales o mayores a 1:32 fueron considerados positivos a anticuerpos neutralizantes contra el VEV serotipo Indiana-1 o New Jersey (OIE, 2010). La asociación entre las variables presencia de anticuerpos contra el VEV y lugar de procedencia de las huanganas fue analizado mediante la prueba de Chi cuadrado empleando el programa SPSS v9.

\section{Resultados}

El 53.4 y $18.2 \%$ de las muestras tuvieron anticuerpos contra los serotipos IND-1 y NJ del VEV, respectivamente (Cuadro 1). En los Cuadros 2 y 3 se presentan la distribución de los títulos de anticuerpos contra cada uno de los serotipos, y en el Cuadro 4 se muestra el porcentaje de animales con anticuerpos neutralizantes igual o mayores a 1:32, según indica la OIE (2010). No hubo asociación entre la seropositividad al VEV y el lugar de muestreo de las huanganas.

\section{Discusión}

Se reporta que el 53.4 y $18.2 \%$ de las muestras de suero de las huanganas presentaron anticuerpos contra los serotipos IND-1 y NJ, respectivamente, con títulos entre 2 a mayores a 256, indicando que estos animales tuvieron contacto con ambos serotipos del VEV presentes en el ecosistema de Madre de Dios. En los reportes mensuales de vigilancia del Servicio Nacional de Sanidad Animal (SENASA, 2011) no mencionan casos 
Cuadro 1. Frecuencia de anticuerpos contra serotipos Indiana (IND-1) y New Jersey (NJ) del Virus de Estomatitis Vesicular (VEV) en suero de huanganas (Tayassu pecari) de tres localidades de Madre de Dios (2008-2009)

\begin{tabular}{lccccc}
\hline \multirow{2}{*}{ Procedencia } & $\begin{array}{c}\text { N. }{ }^{\circ} \text { de } \\
\text { animales }\end{array}$ & $\begin{array}{c}\text { Animales con anticuerpos } \\
\text { contra VEV-IND-1 }\end{array}$ & $\begin{array}{c}\text { Animales con anticuerpos } \\
\text { contra VEV-NJ }\end{array}$ \\
\cline { 2 - 6 } & 30 & $\mathrm{~N}$ & $\%$ & $\mathrm{n}$ & $\%$ \\
\hline Boca de Manu & 10 & 33.3 & 6 & 20.0 \\
Los Amigos & 10 & 9 & 90.0 & 3 & 30.0 \\
Tambopata & 48 & 28 & 58.3 & 7 & 14.6 \\
\hline Total & 88 & 47 & 53.4 & 16 & 18.2 \\
\hline
\end{tabular}

clínicos de estomatitis vesicular u otra enfermedad vesicular en animales domésticos de Madre de Dios, sugiriendo que la infección por el VEV se mantiene en animales silvestres de un nicho ecológico.

En el Perú la epidemiología de la Estomatitis vesicular (EV) en animales domésticos no esta totalmente esclarecida y menos aún en animales silvestres. Si bien ambos serotipos son reportados en animales domésticos, en el país no se dispone de información de la ocurrencia clínica ni reportes serológicos de la EV en huanganas. Wilson et al. (2005) reportó anticuerpos con títulos no mayores a 1:16 contra ambos serotipos del VEV en sajinos (Tayassu tajacu) de apariencia normal criados en cautiverio en Pucallpa e Iquitos.

En el presente estudio se ha detectado una mayor frecuencia del serotipo IND-1 en las hunaganas muestreadas comparadas con el serotipo NJ (Cuadro 1). La significancia de este hallazgo en las huanganas no ha sido establecida. En un estudio realizado en mamíferos silvestres de varias especies (excepto huanganas) en una zona endémica del VEV en Colombia, encontraron en todas las especies capturadas anticuerpos solo contra el serotipo IND-1 aunque con títulos de 1:8 (Ar- boleda et al., 2001). Atwill et al. (1993) analizando varios factores de riesgo asociados a la presencia de la EV en vacas en Costa Rica, encontró factores medioambientales como altitud, precipitación fluvial y vegetación asociados a la infección por el serotipo $\mathrm{NJ}$ pero no al serotipo IND-1, sugiriendo que el ciclo de transmisión del serotipo IND-1 sería diferente al del serotipo NJ.

En estudios realizados en zonas endémicas, se ha reportado $8 \%$ de seroprevalencia del serotipo NJ en sajinos en Arizona (Corn et al., 1987) y $60 \%$ del mismo serotipo en cerdos silvestres en las islas de Ossabaw, Georgia, USA (Stallknecht et al., 2001). En animales domésticos usualmente el serotipo $\mathrm{NJ}$ tiene mayor prevalencia ya que al ingresar el virus a una población susceptible se difunde rápidamente por ser más virulenta que el IND-1 (Atwill et al., 1993; Vanleeuwen et al., 1995; Arboleda et al., 2001).

La frecuencia de animales con títulos de anticuerpos neutralizantes igual o mayor a 1:32, según lo indicado por el OIE (2010), contra los serotipos IND-1 (29.5\%) y NJ (2.3\%) (Cuadro 4) indican reacciones específicas. Los títulos menores a 1:32 son considerados inespecíficos pero no se han realizados estudios para conocer el tipo de proteína 
Cuadro 2. Distribución de los títulos de anticuerpos contra el serotipo Indiana (IND-1) del Virus de Estomatitis Vesicular (VEV) en sueros de huanganas (Tayassu pecari) de tres localidades de Madre de Dios (2008-2009)

\begin{tabular}{lccccccc}
\hline \multirow{2}{*}{ Procedencia } & $\begin{array}{c}\text { N. }{ }^{\circ} \text { de } \\
\text { animales }\end{array}$ & \multicolumn{9}{c}{ Inversa de los títulos de anticuerpos contra } & Total de \\
\cline { 3 - 7 } & & $2-4$ & $8-16$ & $32-64$ & $128-256$ & $>256$ & \\
\hline Boca de Manu & 30 & - & 5 & 3 & 2 & - & 10 \\
Los Amigos & 10 & 1 & 4 & 3 & 1 & - & 9 \\
Tambopata & 48 & 3 & 8 & 14 & 1 & 2 & 28 \\
\hline Total & 88 & 4 & 17 & 20 & 4 & 2 & 47 \\
\hline
\end{tabular}

Cuadro 3. Distribución de los títulos de anticuerpos contra el serotipo NJ del Virus de Estomatitis Vesicular (VEV) en sueros de huanganas (Tayassu pecari) de tres localidades de Madre de Dios (2008-2009)

\begin{tabular}{lccccccc}
\hline \multirow{2}{*}{ Procedencia } & \multirow{2}{*}{$\begin{array}{c}{ }^{\circ} \text { de } \\
\text { animales }\end{array}$} & \multicolumn{5}{c}{ Inversa de los títulos de anticuerpos contra } & \multirow{2}{*}{$\begin{array}{c}\text { Total de } \\
\text { Veactores }\end{array}$} \\
\cline { 3 - 8 } & $2-4$ & $8-16$ & $32-64$ & $128-256$ & $>256$ & \\
\hline Boca de Manu & 30 & 4 & 2 & - & - & - & 6 \\
Los Amigos & 10 & - & 2 & 1 & - & - & 3 \\
Tambopata & 48 & 3 & 3 & 1 & - & - & 7 \\
\hline Total & 88 & 7 & 7 & 2 & - & - & 16 \\
\hline
\end{tabular}

Cuadro 4. Número de sueros con títulos de anticuerpos igual o mayor a 1:32 contra los serotipos IND-1 y NJ del Virus de Estomatitis Vesicular (VEV) según lo indica la OIE (2010)

\begin{tabular}{|c|c|c|c|c|c|c|}
\hline \multirow{4}{*}{ Procedencia } & \multicolumn{6}{|c|}{ Inversa de los títulos de anticuerpos contra } \\
\hline & \multirow{3}{*}{$\begin{array}{l}\mathrm{N} .^{\circ} \text { de } \\
\text { sueros }\end{array}$} & \multirow{2}{*}{\multicolumn{2}{|c|}{$\begin{array}{c}\text { VEV IND-1 } \\
32 \text { a }>256\end{array}$}} & \multirow{2}{*}{\multicolumn{2}{|c|}{$\frac{\text { VEV NJ }}{32 \mathrm{a}>256}$}} & \multirow{3}{*}{ Total } \\
\hline & & & & & & \\
\hline & & $\mathrm{n}$ & $\%$ & $\mathrm{n}$ & $\%$ & \\
\hline Boca de Manu & 30 & 5 & 16.6 & 0 & 0 & 5 \\
\hline Los Amigos & 10 & 4 & 40.0 & 1 & 10.0 & 5 \\
\hline Tambopata & 48 & 17 & 35.4 & 1 & 2.1 & 18 \\
\hline Total & 88 & 26 & 29.5 & 2 & 2.3 & 28 \\
\hline
\end{tabular}


capaz de neutralizar al VEV hasta 1:16 o que fueron anticuerpos de reciente aparición o de extinción. Los títulos mayores a 1:256 en dos de los animales podría indicar una infección activa, aunque de tipo subclínico, ya que ninguno de las huanganas mostraron sintomatología clínica ni lesiones en piel o mucosas durante el muestreo. La zona de Tambopata presentó la mayor proporción de huanganas con anticuerpos específicos contra el serotipo IND-1, sugiriendo la existencia de un nicho ecológico favorable para los insectos transmisores o animales reservorios del virus.

El conocimiento de las enfermedades en poblaciones de animales silvestres del país es pobre. Esto, sumado a los cambios climáticos y reducción sistemática del ecosistema de los animales silvestres por el hombre, constituyen factores de riesgo que podrían afectar la salud de los animales silvestres como también del hombre. Estos resultados muestran la importancia de mantener una vigilancia del VEV en las huanganas y en otras especies silvestres, como los murciélagos, no sólo en Madre de Dios, sino también en otras áreas tropicales del país por ser estos últimos reservorios de muchos agentes virales.

\section{ConClusiones}

Los serotipos Indiana-1 y New Jersey del virus de Estomatitis Vesicular están presentes en huanganas (Tayassu pecari) de vida libre en la zona de Madre de Dios.

\section{Literatura Citada}

1. Arboleda JJ, Restrepo G, Wolff MI, Uribe JH, Bedoya HA, Quiróz VH, Pérez S, et al. 2001. Ecoepidemiología de la estomatitis vesicular en un municipio cafetalero de Antioquia. Rev Col Cienc Pec 14(1): 20-27.
2. Atwill E, Rodríguez LL, Hird DW, Rojas O. 1993. Environmental and host factors associated with seropositivity to New Jersey and Indiana vesicular stomatitis virus in Costa Rica. Prev Vet Med 15:303-314.

3. Beldoménico PM. 2008. Enfermedad y fauna: foco de creciente interés para las ciencias biomédicas. APRONA Bol Cien 40: 46-55.

4. Bodmer R, Aquino R, Puertas P, Reyes C, Fang T, Gottdenker N. 1997. Manejo y uso sustentable de pecaríes en la Amazonía peruana. Quito, Ecuador: Unión Internacional para la Conservación de la Naturaleza y los Recursos Naturales (UICN). 102 p.

5. Bodmer R, Fang T, Villanes $R$, Puertas P. 2004. Certification of the peccary pelt trade: a strategy for a managing bush meet hunting in the Peruvian Amazon. IUCN/SSC Pigs, Peccaries, and Hippos Specialist Group (PPHSG) Newsletter 4(1): 5-12.

6. Cleaveland S, Hess GR, Dobson A, Laurenson MK, McCallum HI, Roberts M, Woodroffe R. 2002. The role of pathogens in biological conservation. In Hudson PJ, Rizzoli A, Grenfell BT, Heesterbeek H, Dobson AP (eds). The ecology of wildlife diseases. Oxford, UK: Oxford University Press. p 139-150.

7. Corn J, Lee RM, Erickson GA, Murphy DC. 1987. Serologic survey for evidence of exposure to vesicular stomatitis virus, pseudorabies virus, brucellosis, and leptospirosis in collared peccaries from Arizona. J Wildlife Dis 23: 551-557.

8. Fragoso J. 1997. Desapariciones locales del báquiro labiado (Tayassu pecari) en la Amazonía: ¿Migraciones, sobrecosecha o epidemia? En: Manejo de fauna silvestre en la Amazonía. La Paz: UNAP. p 309-312.

9. Karesh W, Uhart M, Painter L, Wallace R, Braselton E, Thomas LE, Mc Namara T, Gottdenker N. 1998. Health evaluation of white-lipped 
peccary populations in Bolivia. In: Proc AAZV-AAWV Joint Conference. Santa Cruz, Bolivia. p 445-449.

10. [OIE] Organización Mundial de Sanidad Animal. 2010. Pruebas de diagnóstico prescritas y de sustitución para las enfermedades de la lista de la OIE. París: OIE. Código sanitario para los animales terrestres 1 (Cap.1, 3). 144 p.

11. Painter L. 1996. Aspectos de salud poblacional y la biología reproductiva del pecarí de labio blanco, Tayassu pecari, en el Parque Nacional Noel Kempff Mercado. Bol Bolfor 9:11-14.

12. [SENASA] Servicio Nacional de Sanidad Animal. 2011. [Internet], [5 agosto 2011]. Disponible en: http:// www.senasa.gob.pe/RepositorioAPS/0/ 1/JER/ANRIEVIEP_REPEPISEMA/ S.E.\%2034\%20SENASA-2011.pdf

13. Real V, Dutra V, Nakasato L, Freitas T, Keuroghlian A, Arleana A, Souza R. 2010. PCR de Salmonella sp, Streptococcus suis, Brucella abortus e circovirus suino tipo 2 em Taiassuideos de vida livre e cativeiro. Rev Bras Saúde Prod An 11: 858-864.

14. Reis Jr JL, Mead D, Rodríguez LL, Brown CC. 2009. Transmission and pathogenesis of vesicular stomatitis virus. Braz J Vet Pathol 2: 49-58.

15. Rodríguez L. 2002. Emergence and reemergence of vesicular stomatitis in the United States. Virus Res 85: 211-219.

16. Romero M. 2010. Evaluación sanitaria de la presencia de enfermedades y caracterización de los patrones de caza de subsistencia de la huangana (Tajassu pecari) de vida libre en la Amazonía peruana. Tesis de Maestría. Sao Paulo: Escuela Superior de Agricultura, Univ. de Sao Paulo. 62 p.

17. Stallknecht D, Perzak DE, Bauer LD, Murphy MD, Howerth EW. 2001. Contact transmission of vesicular stomatitis virus New Jersey in pigs. Am J Vet Res 62: 516-520.

18. Vanleeuwen J, Rodríguez L, WaltnerToews D. 1995. Cow, farm and ecologic risk factors of clinical vesicular stomatitis on Costa Rican dairy farms. Am J Trop Med Hyg 53: 342-350.

19. Wilson A, Arainga M, Gálvez H, Manchego A, Rivera H. 2005. Anticuerpos contra el virus de la estomatitis vesicular en sajinos (Tayassu tajacu) de zoocriaderos de Iquitos y Pucallpa. Rev Inv Vet, Perú 16: 180-183. 